\title{
Historia constructiva del Complejo Monástico de la Compañía de Jesús en el Casco Antiguo de Panamá y análisis de su tutela.
}

\section{Patricia Cid $^{1 *}$ y Berta Cardoze ${ }^{2}$}

${ }^{1}$ Profesora e investigadora, Facultad de Arquitectura y Diseño, Universidad Católica Santa María la Antigua.

${ }^{2}$ Catedrática, Facultad de Arquitectura y Diseño, Universidad Católica Santa María la Antigua de Panamá y Facultad de Arquitectura, Universidad de Panamá.

* Autor para correspondencia. Email: pcidl@usma.com.pa; p.cid@,casinicidarchitetti.it

Recibido: 09 de junio de 2018

Aceptado: 19 de julio 2018

\section{Resumen.}

El Complejo de la Compañía de Jesús ha sido formado en su historia constructiva, por edificios e iglesias realizados a finales del siglo XVII y a mediados del siglo XVIII que representan etapas significativas en el desarrollo de la sociedad colonial española en Panamá y de sus locales. Sus atributos forman parte y transmiten el "Valor Universal Excepcional" del Casco Antiguo de Panamá los cuales, se ven reflejados en la traza urbana, la dimensión y distribución de los lotes de terreno asignados y en sus características iniciales de fortaleza realizadas por las órdenes religiosas dentro de este Centro Histórico.

En la actualidad, el polígono que ocupaban sus edificaciones son parte de una única unidad de reconocido valor urbano, arquitectónico e histórico debido al proceso evolutivo que encierran las características estéticas y constructivas de su Complejo, a su condición original de "conjunto urbano” y, a la importancia religiosa y de instrucción académica y moral que realizó la Orden de la Compañía de Jesús desde sus inicios como Colegio Seminario en el siglo XVII y primeras décadas del siglo XVIII hasta que se edificó la Real y Pontificia Universidad de San Javier de Panamá en el siglo XVIII la cual, además, fue la primera universidad en el país y que pretendió alcanzar una posición de reconocimiento en América, al nivel de las prestigiosas Universidades de Bogotá, Quito y Lima.

Palabras clave. Monumento Histórico; Patrimonio Arquitectónico; Patrimonio Urbano; Tutela UNESCO; Conservación del Patrimonio Cultural. 
Invest. pens. crit. (ISSN 1812-3864)

Vol. 6, No. 2, mayo-agosto 2018

pp. $30-51$

\begin{abstract}
.
The Complex of the Society of Jesus has been formed in its constructive history, by buildings and churches made in the late seventeenth and mid-eighteenth century that represents significant stages in the development of Spanish colonial society in Panama and its premises. Its attributes are part and transmit the "Outstanding Universal Value" of Panama's Old Quarter, which are reflected in the urban layout, the size and distribution of assigned lots of land and initial strength characteristics made by religious orders inside this Historical Center.
\end{abstract}

At present, the land that occupied their buildings are part of a single unit of recognized urban, architectural and historical value due to the evolutionary process that enclose the aesthetic and constructive characteristics of its Complex, to its original condition as an "urban group" and to the religious and academic and moral importance that the Order of the Society of Jesus made from its beginnings as a Seminary College in the 17th century and first decades of the 18th century until the Royal and Pontifical University of San Javier in Panama in the 18th century, which, moreover, it was the first university in the country and sought to achieve a position of recognition in America, at the level of the prestigious Universities of Bogotá, Quito and Lima.

Keywords. Historical Monument; Architectural Heritage; Urban Heritage; UNESCO Tutelage; Cultural Heritage Conservation

\title{
1 Introducción
}

La siguiente investigación ha permitido definir el origen y comprensión de los límites históricos de la propiedad del Conjunto Monumental asignados a la Orden Religiosa de la Compañía de Jesús en 1673, a causa del traslado de la primera ciudad de Panamá - hoy llamada Panamá Viejo - a su nuevo asentamiento en las faldas del Cerro Ancón, conocido en la actualidad como Casco Antiguo. Además de, determinar la relación histórico - arquitectónica y cultural entre las edificaciones a través de su proceso constructivo y de las funciones para las cuales, fueron destinadas.

De acuerdo con el plano de lotizaciones del Corregimiento de San Felipe, el Complejo Jesuita se encuentra ubicado en la Manzana 29, con la exposición frontal dirigida hacia la Avenida A y sus laterales, hacia las calles $7^{\circ}$ Oeste y $8^{\circ}$ Oeste, del Conjunto Monumental Histórico del Casco Antiguo de la Ciudad de Panamá y reconocido como Patrimonio Mundial UNESCO, protegido y amparado por su inscripción desde 1997 la cual, confirma el valor excepcional y universal del sitio para el beneficio de la bumanidad $^{1}$. La Manzana 29 está conformada por los lotes 2471, 2473, 2476, 2479 y 3045 de los cuales, el 2471 y 2479 corresponden a los edificios de la Real y Pontificia Universidad de San Javier, 2476 y 3045 a la Iglesia de la Compañía de Jesús, y el 2473 al patio central del complejo.

Se individuaron tres fases constructivas que hacen referencia a los siguientes períodos: establecimiento territorial de la Orden Jesuita en el lote de apartenencia y construcción de las primeras edificaciones

\footnotetext{
${ }^{1}$ Ley N51 del 2004: "Manual de Normas y Procedimientos para la Restauración y Rehabilitación del Casco Antiguo de la Ciudad de Panamá", Título II, Capítulo I, Artículo 5:

"Se entenderá que todas las propiedades existentes dentro de los límites del Casco Antiguo estarán protegidas y amparadas por la Inscripción del Comité del Patrimonio Mundial de la Organización de las Naciones Unidas para la Educación, la Ciencia y la Cultura (UNESCO), del 6 de diciembre de 1997, en la lista del patrimonio mundial y en el cual se confirma el valor excepcional y universal del sitio para el beneficio de la humanidad, además de cualquier otra normativa legal vigente en la República de Panamá".
} 
Invest. pens. crit. (ISSN 1812-3864)

Vol. 6, No. 2, mayo-agosto 2018

pp. $30-51$

del Colegio de San Javier (1673 - 1737), realización del complejo monástico de la Real y Pontificia Universidad de San Javier (1737 - 1821), y fraccionamiento del Complejo Jesuita, venta de las propiedades y posteriores modificaciones arquitectónicas $(1821-\mathrm{s} . \mathrm{XX})$.

En origen, el trazado urbano dibujado por Bernardo de Ceballos y Arce $^{2}$ en el Detalle del Plano de 1688 de la Ciudad de Panamá muestra a la actual Manzana 29 del Casco Antiguo, dividida en dos. Un polígono donde se aprecia claramente la designación a la Orden Religiosa con la escrita "La Comp.a" (diminutivo de "Compañía") que permite identificar el actual terreno correspondiente a la Fincas 2476, $3045,2473,2471$ y 2479. Y un segundo polígono, conformado por 4 lotes de construcciones perimetrales y patios centrales correspondientes al origen de las Fincas 3850, 3708, 1820, 2459 y 456. Ambos separados por una Calle que colegaba a las actuales Calles $7 \mathrm{ma}$ Oeste y 8va Oeste. Ver Fig. $N^{\circ} 1$

El polígono de la Compañía de Jesús, además, se muestra amurallado perimetralmente, así como también, el polígono de La Catedral identificado por su escrita y ubicado en la posición inferior. La Prof. Carmen Mena García, Profesora de la Universidad de Sevilla y Doctora en Historia de América con especialización en el área centroamericana, nos lo explica en el siguiente extracto:

"La conciencia colectiva urbana va dejando atrás la idea de una ciudad abierta, "ciudad mercado", como lo fuera por mucho tiempo Panamá la Vieja, y sustituyéndolo por un nuevo modelo urbano, el de ciudad fortificada, en donde perfectamente tiene cabida la tripartición funcional indoeuropea que combina lo sagrado, lo militar y lo económico [...] Las murallas cargadas de simbolismo definen un espacio de poder y de derecho concreto, un espacio también religioso, siendo incluso un monumento consagrado [...]”3

Esto nos evidencia el vínculo histórico de las edificaciones que se originarán dentro de este espacio. Se trata de una única propiedad que nace amurallada para separar las actividades de la Orden Jesuita de las del resto de la ciudad bajo un fuerte aspecto: el de separar lo sagrado de lo mundano, así como, del tema defensivo que no seguirá la experiencia vivida en Panamá la Vieja. De este modo, a este espacio se le da un alto valor ante la sociedad colonial de la época y que, además, declara una característica arquitectónica y urbana bien precisa de los inicios de la historia de la ciudad del Casco Antiguo, de las últimas décadas del siglo XVII.

Seis décadas después, en el trazado del Plano de Panamá de 1749 del ingeniero militar Nicolás Rodríguez ${ }^{4}$, se aprecia que las edificaciones del polígono de la Compañía de Jesús han avanzado hacia estos lotes ocupando la Calle que en el Plano de Bernardo de Ceballos y Arce conectaba a la actual Calle $7 \mathrm{ma}$ Oeste con la 8va Oeste. En cuanto al segundo polígono, éstas se mantienen en la misma posición pero, el ancho de los 4 lotes originales cambia y se subdividen hasta conformar los 5 lotes actuales. De este modo, la conformación actual de la denominada Manzana 29, ha quedado establecida. Ver Fig. $N^{\circ} 2$

\footnotetext{
${ }^{2}$ Ingeniero militar de la corona española quien dirigió en gran parte la construcción del recinto defensivo para la nueva ciudad de Panamá durante el siglo XVII.

${ }^{3}$ MENA GARCIA, Carmen. Panamá en el siglo XVIII: trazado urbano, materiales y técnica constructiva. Revista de Indias, vol. LVII, núm. 210, 1997, pp. 372

${ }^{4}$ En 1731 es nombrado Ingeniero Ordinario del Real Cuerpo de Ingenieros y es enviado a servir en América. Se encuentra en Panamá desde 1745 en la costa atlántica y en la Ciudad de Panamá. (CAPEL, 1983, p. 405)
} 
Invest. pens. crit. (ISSN 1812-3864)

Vol. 6, No. 2, mayo-agosto 2018

pp. $30-51$

\section{Primera fase constructiva: las primeras edificaciones del Colegio de San Javier}

Las primeras edificaciones que surgen dentro del polígono de la Compañía de Jesús, se observan en el Plano de 1688 de Ceballos y Arce. Son dos y se posicionan en forma de "L", en la esquina entre las actuales Avenida A y Calle 8va Oeste lo que, correspondería a las Fincas 2471 y 2479 . Ver Fig. No1

El Plano muestra a la Iglesia de la Compañía de Jesús bajo la misma representación gráfica utilizada para identificar a La Catedral confiriendo a ambas, un aspecto de importancia y de fácil reconocimiento de la arquitectura religiosa. En contraste, el Colegio de San Javier de Panamá se aprecia con un aspecto muy simple, de volumen alargado y con un techo a dos aguas lo que, confirmaría las siguientes descripciones:

"Cuando dos años más tarde, en Enero de 1673, el nuevo Gobernador D. Antonio Fernández de Córdobay Mendoza trasladó la nueva ciudad al sitio llamado de Ancón, que boy ocupa, a unos ocho kilómetros al Oeste de la antigua, los Jesuitas obtuvieron sin dificultad que en el repartimiento de solares se les señalase uno para la futura casa e iglesia. Mas, como en la común desgracia el capital de la fundación que acabamos de hablar se perdio por completo, y ninguno de los vecinos arruinados por el saqueo les podía ayudar, nuestros Padres, en señal de haber tomado posesión del solar que la ciudad les habia concedido, no tuvieron otra cosa que poner sino una cruz con una tablilla que llevaba inscrito el monograma de IHS [...]

$[\cdots]$

4.- Cuando en Agosto de 1690 el P. Diego Francisco Altamirano biz̧o la visita al colegio de Panamá, quedó dolorosamente impresionado por la extremada pobreza rayana en miseria, en que vivían nuestros Padres [...] [...]

Si el colegio era pobre, la iglesia por el contrario, gracias a los donativos de personas piadosas estaba bastante bien provista y adornada [...]" 5

Estas diferencias confirman las representaciones de Bernardo de Ceballos y Arce y de las estructuras de una casa también llamada colegio y de una iglesia en el polígono de la Compañía de Jesús para el año de 1688. Estas condiciones del complejo edificado perdurarán hasta el 2 de febrero de 1737, cuando serán devastadas por el incendio conocido como "el Fuego Grande" que consumió las 2/3 partes del Casco Antiguo ${ }^{6}$ las cuales, se describen a continuación:

"5.- La situación económica del colegio de Panamá siguió siendo precaria durante el siglo SVIII, pues encontramos en 1741 al P. Rector Ignacio Cayroni afanándose trabajosamente en reconstruir la casa y la iglesia, que habian sido destruidas en uno de aquellos incendios que de vez en cuando asolaban la ciudad, causando en ellas terribles estragos, por ser de madera la mayor parte de las construcciones [...]” 7

La pobreza extrema de las condiciones de los Jesuitas para aquel entonces, obligaron a edificar el Colegio de la Orden y la Iglesia en madera y por esta razón, fueron devastadas por el incendio de 1737. Cabe destacar, que la praxis habitual de la edilicia de este período era la construcción en madera por su rápida realización y bajo costo, pese al peligro que este material implicaba. Por otro lado,

\footnotetext{
${ }^{5}$ JOUANEN S.I., José. Historia de la Compañia de Jesús en la antigua Provincia de Quito 1570 - 1773, Tomo II, La Provincia de Quito, 1696 - 1773. Editorial Ecuatoriana, 1943, pp. 179 - 182.

6 TEJEIRA, Eduardo y SPADAFORA, Vanesa. El Casco Antiguo de la Ciudad de Panamá. Oficina del Casco Antiguo. Panamá, 2001, pp. 33.

${ }^{7}$ JOUANEN S.I., José. Historia de la..., op. cit., p. 182.
} 
Invest. pens. crit. (ISSN 1812-3864)

Vol. 6, No. 2, mayo-agosto 2018

pp. 30-51

también se contaba con buenos artesanos que llegaban a realizar estupendas elaboraciones arquitectónicas e importantes decoraciones con este material. Por lo que, era un material que venía utilizado tanto en una edilicia pobre como en ambientes más refinados. Lo que no se especifica es si alguna de las edificaciones o ambas contaron con cimientos en mampostería o no.

Basándonos en ambas fuentes, se llega a la conclusión que ambos edificios correspondían, uno al Colegio Jesuita y el otro, a la Iglesia de la misma. El Colegio identificado por la estructura ubicada en la posición de la Finca 2479 y la Iglesia, en cambio, en la Finca 2471.

\section{Segunda fase constructiva: la Real y Pontificia Universidad de San Javier}

Después del Fuego Grande, el Padre Francisco Javier Luna Victoria retoma la intención de $1651^{8}$ de crear dos Cátedras, una en Filosofía y otra en Teología Moral e iniciar los estudios mayores en un nuevo colegio en Panamá, con la intención de evitar que los estudiantes del Colegio de San Javier tuviesen que trasladarse a las Universidades de Quito o de Lima para continuar con su instrucción. Por esta razón, en 1740 envía una petición al Padre General quien acepta la fundación de estas dos Cátedras, en carta de $1742^{9}$.

En esta nueva fase, las murallas perimetrales del polígono de la Compañía de Jesús desaparecen. El nuevo Colegio y Casa de la Orden de los Jesuitas, se edifican en la misma posición precedente, manteniendo el mismo uso interno. Esta vez, en mampostería como lo apreciamos en la actualidad. Así, lo testimonian la Vista Volumétrica dibujada por el ingeniero Nicolás Rodríguez en 1748 (ver Fig. $N^{\circ}$ ) y el siguiente escrito:

"[...] A 7 de Septiembre de 1741 da cuenta el P. Cayroni del estado en que por entonces se hallaban las obras. La casa estaba y a casi terminada, faltando solamente las divisiones del segundo piso que habian de ser de tablas o de bahareque, según lo que se pudiese haber. Para esto habia tenido, que endendarse en la suma de 3000 pesos $[\ldots]^{\prime \prime 10}$

Después del incendio de 1737 hasta 1741, han pasado 4 años donde los Jesuitas han tenido que ser reubicados en un sitio que se desconoce pero, que durante este período, el tiempo ha sido empleado en la realización del nuevo Colegio. La duración de la construcción y la importante suma invertida para la época confirman su ejecución en un sistema más sólido y resistente, después de la experiencia apenas sufrida: un sistema en muros de mampostería, estructura interna en madera y subdivisiones en tablas o bahareque. Una práctica edilicia común entre los sistemas constructivos de la época.

\footnotetext{
${ }^{8}$ BORDA, José Joaquín. Historia de la Compañia de Jesús en la Nueva Granada. Poissy Imprenta de S. Lejay et C, vol. 1., 1872, pp. 39 y 40:

"Don José Alvaro Alonzo y Mesa y su esposa, doña Beatriz. Montero, fundaron el colegio de San Javier de Panamá en agosto de 1651, " a fin de que, dice la escritura de fundación, el dicho colegio tenga lo necesario para su fábrica de iglesia y sustento de los religiosos que lo habitan y lo han de habitar. »Para esto dieron la suma de 40,000 pesos, manifestando su deseo de que se estableciesen cátedras de filosofía y teología [...] Estas clases no pudieron abrirse hasta el año de 1744, en que el sacerdote panameño, Don Francisco Javier de Luna Victoria, despues obispo de Panamá y de Trujillo, señaló de su peculio 6,900 pesos de renta; y se obtuvo, á petición de la Audiencia, que se erigiese el Colegio en Universidad."

9 JOUANEN S.I., José. Historia de la..., ibídem, p. 233.

${ }^{10}$ JOUANEN S.I., José. Historia de la..., ibíd, p. 182.
} 
Invest. pens. crit. (ISSN 1812-3864)

Vol. 6, No. 2, mayo-agosto 2018

pp. $30-51$

El nuevo Colegio estará conformado por dos edificios, los correspondientes a las Fincas 2479 y 2471 , que a partir del 17 de abril de $1744^{11}$ pasará a llamarse: la Real y Pontificia Universidad de San Javier y brindará tres Cátedras, en vez de, dos; y con el Padre Hernando Cavero, como primer rector. El edificio de la Finca 2471 será dedicado a la Cátedra de Filosofía; mientras que, el de la Finca 2479, comprenderá las Cátedras de Moral en el primer alto y de Teología Escolástica, en el segundo.

“[...] Como acto previo a la fundación, D. Francisco Javier Luna Victoria presentó el 30 de Enero de 1744 a la Real Audiencia el acta de donación de las rentas necesarias para su sostenimiento... por lo que quiere eregir tres cátedras, una de Filosofía y otras dos de Teología escolástica y moral... él ofrece para la cátedra de Filosofía un principal de 6000 pesos, que se ha de situar sobre dos casas suyas, por mitades... Para la cátedra de Moral ofrece levantar a sus expensas en el solar del Colegio de la Compañía, que se quemó en 1737, un edificio nuevo de caly canto de 8 lumbres de frente, que hace 40 varas, y 12 varas dos tercios de ancho, de un solo alto... Para la cátedra de Teología se hará sobre este mismo edificio otro segundo piso [...]"

Definitivamente, 6000 pesos se requieren para una gran estructura lo que, corresponde al mayor volumen presente en la Vista Volumétrica del ingeniero Rodríguez (ver Fig. $N^{\circ} 3$ ). Esto confirma la realización del segundo edificio del polígono de la Compañía de Jesús, denominado como Finca 2471. Por otro lado, la descripción sobre la posición del edificio para las Cátedras de Moral y Teología es claro, así como, su dimensión de 8 lumbres de frente que corresponderían a 36 metros aproximados con los que, cumple el edificio en su actualidad en la Finca 2479.

Los siguientes tres años después de su fundación en 1744, la Real y Pontificia Universidad de San Javier pasa por algunos problemas que la llevan a no contar con los maestros necesarios para impartir lecciones ni con una cantidad de alumnos suficientes para mantener la Cátedra de Filosofía. Es por esto, que el Padre Guillermo Grebmer, Padre Viceprovincial, decide cerrarla en febrero de 1748 y no viene reactivada sino, hasta el 3 de junio de 1749 por aprobación de la Real Audiencia, después de haber resuelto estos problemas ${ }^{12}$. Su clausura total, en cambio, se da en 1767, cuando el Rey Carlos III decreta la expulsión de la Orden Jesuita del territorio español y de todas sus propiedades en las colonias.

\section{Segunda fase constructiva: la Iglesia de la Compañía de Jesús}

En cuanto a la nueva Iglesia, después del Fuego Grande de 1737, se optó por una estrategia contraria a la inicial. Esta vez, los Jesuitas se concentrarán en invertir en una mejor edificación - en el nuevo Colegio - y realizarán una estructura temporal de rápida y poco costosa construcción donde poder impartir la liturgia, mientras que, reúnen económicamente lo necesario para poder realizar una Iglesia digna. La edificación temporal viene posicionada en el actual Patio del Convento (Finca 2473), en los límites con el sitio elegido para la nueva Iglesia (Fincas 2476 y 3045).

"[...] También se estaba trabajando en la capilla provisional, que era de madera [...] Esta capilla de seis lumbres de largo y cuatro de ancho se levantó en el sitio que después habia de servir de patio, en tanto que se iba construyendo una iglesia de cal y ladrillo.

${ }^{11}$ Ibid, p. 235.

12 Ibid, p. $235-241$. 
Invest. pens. crit. (ISSN 1812-3864)

Vol. 6, No. 2, mayo-agosto 2018

pp. $30-51$

$[\cdots]$

Como el P. Cayroni no había tenido ocasión de enviar la carta escrita el 7 de septiembre de 1741, a 16 de noviembre añade en la misma algunos pormenores interesantes: «La obra de la casa, dice sigue adelante; la capilla provisional se va perfeccionando al lado del solar reservado a la nueva iglesia. Para que esta pueda ser en un todo igual a la que se quemó, se han de gastar a lo menos 4000 pesos en ella, y de estos 4000 pesos no hay recogidos hasta abora sino la confianza en Dios》》 [... $]^{13}$

El cambio de ubicación de la Iglesia se debió a que la posición anterior (Finca 2471) estaba siendo ocupada por la construcción del nuevo edificio dedicado a la Cátedra de Filosofía de la Universidad Javeriana. Por esta razón, la capilla provisional viene colocada en el Patio del Convento (Finca 2473) dejando la posición angular, entre la actual Calle $7 \mathrm{ma}$ Oeste y la Avenida $\mathrm{A}$, a la que sería la nueva Iglesia a realizarse en cal y ladrillo. Ver Fig. $\mathrm{N}^{\circ} 3$

Se confirma además, que ambas estructuras (el nuevo Colegio en plena construcción y la nueva Iglesia que se quiere eregir) son de importantes valores económicos los cuales, determinan que las tres edificaciones son de características constructivas similares: sólidas y resistentes (mampostería). Con la acentuación de que la Iglesia como tal, es destinada a poseer una mayor riqueza estética y decorativa. En la frase: "todo igual a la que se quemó", se hace también referencia al edificio eclesiástico anterior ubicado en la actual Finca 2471 lo que, testimonia que éste era de una cierta importancia arquitectónica y constructiva, dándole mayor peso a la representación gráfica realizada por Bernardo de Ceballos y Arce en 1688. Ver Fig. $N^{\circ} 1$

La primera piedra para la construcción de la Iglesia de la Compañía de Jesús ubicada en las actuales Fincas 2476 y 3045, se dio el 2 de febrero de 1761 14 , 20 años más tarde de la capilla provisional en madera. De acuerdo con la realización descrita en "cal y ladrillo" de 1741, se asume que hayan utilizado sus propios productos constructivos, ya que, la huerta del Colegio de la Compañía contaba con un horno de ladrillos el cual, a su vez, no sólo brindó el material para la Iglesia de la Compañía sino, que también dio ladrillos para la construcción de la Catedral.

"[...] porque teniendo la buerta un horno de ladrillos, el colegio se obligó a dar cierto número de éstos para la construcción de la catedral que se estaba levantando. (1)" 15

Por otro lado, Ernesto Castillero también nos informa que los materiales para la construcción de la Iglesia provenían de Panamá La Vieja, donde eran extraídos de las ruinas de la ciudad abandonada. ${ }^{16}$ Se refería a la piedra que se utilizaría en la fachada y los muros.

${ }^{13}$ Ibid, p. $182-183$.

${ }^{14}$ CASTILLERO, Ernesto J. Convento y templo de la Compañia de Jesís. Revista Lotería Nº183, febrero de 1971, pp. 65

${ }^{15}$ JOUANEN S.I., José. Historia de la..., ibíd, p. 242.

"(1) He aquí lo que el colegio debia dar: "De los ladrillos ya fabricados para la catedral: 6.000 ladrillos chicos para la corniza, 8.500 ladrillos cuadrados para el suelo, 6.500 cuadrados dobles para el altozano. Además debia fabricar y tener preparados en la buerta para cuando se necesitasen: 6.300 ladrillos cuadrados ordinarios, 3.250 cuadrados dobles, 21.200 ladrillos chicos ordinarios y 1.000 chicos gordos $\gg . "$

${ }^{16}$ CASTILLERO, Ernesto J. Convento y templo..., ibídem, p. 65 
Invest. pens. crit. (ISSN 1812-3864)

Vol. 6, No. 2, mayo-agosto 2018

pp. $30-51$

No se encontraron datos sobre la fecha exacta de culminación de la Iglesia pero, en el mapa de la Ciudad de Panamá del ingeniero militar Manuel Hernánde $z^{17}$ de 1765 , ya viene representada (ver Fig. $N^{\circ} 4$ ). Dos años más tarde, la Iglesia viene despojada de sus haberes con la expulsión de los jesuitas de nuestro territorio. El Complejo Monástico de la Compañía de Jesús resta en pie hasta 1781 cuando las edificaciones clausuradas de la Real y Pontificia Universidad de San Javier y de la Iglesia de la Compañía de Jesús son devastadas por un incendio ${ }^{18}$ y sus estructuras son abandonadas hasta convertirse en ruinas.

\section{Tercera Fase: Fraccionamiento del Complejo Jesuita, venta de las propiedades y posteriores modificaciones arquitectónicas}

El Complejo de la Compañía de Jesús estuvo abandonado hasta 1865 con excepción de la Finca 2479 correspondiente al edificio de la antigua Cátedra de Teología y Moral que entre los años 20 y 40 de este siglo, estuvo ocupada por la Familia De Obarrio y en 1859, pasó de residencia a convertirse en el Hotel Washington ${ }^{19}$. Ver Fig. $N^{\circ} 5$

En 1851, en cambio, el estado se interesa en asignar una importante suma de dinero para restaurar el edificio de la antigua Cátedra de Filosofía (Finca 2471), con la finalidad de recuperarlo y utilizarlo en oficinas públicas. Esto no se hace efectivo y tres años más tarde, se autoriza la venta de todo el Complejo de la Compañía de Jesús para destinar lo recaudado a las escuelas primarias de algunas provincias en el interior del país. La subasta finalmente se realiza en 1865, y la Compañía de Jesús (Universidad e Iglesia) es adquirida por el Banco Planas ${ }^{20}$ quien, a su vez, decide revender la propiedad fraccionándola en los actuales lotes que conocemos. Los edificios que funcionaban para la antigua Universidad Javeriana corresponderán a las Fincas 2479 y 2471; el Patio será la Finca 2473; y la Iglesia Jesuita será dividida en dos lotes, las Fincas 2476 para la nave y la 3045, para la sacristía. Ver Fig. $N^{\circ} 1$ y 2

En la última década del siglo XIX, se inaugura el Club Internacional en el edificio de la antigua Cátedra de Teología y Moral (Finca 2479). Mientras que, el terremoto de 1882 afecta fuertemente al edificio de la antigua Cátedra de Filosofía (Finca 2471) provocando el desplome del área central hacia la Avenida A que pierde, fundamentalmente, la fachada principal con el portal de arcadas (con excepción de los muros de las esquinas del pórtico que mantienen los antiguos accesos desde Calle $8^{\mathrm{a}}$ Oeste y la plazoleta de ingreso a la Iglesia) y el área del muro con uno de los dos ingresos monumentales del edificio (el izquierdo). Posteriormente, los muros restantes que quedaron en pie del área central serán reutilizados e integrados con una nueva estructura para completar la fachada, se tapearán los vanos laterales del pórtico, se reorganizará la distribución de las ventanas y se incluirán

\footnotetext{
${ }^{17}$ Ingeniero militar del Real Cuerpo de Ingenieros. Opera en las fortificaciones de Portobelo y San Lorenzo desde 1753 hasta 1761 para luego, pasar a la Ciudad de Panamá donde interviene en la muralla defensiva, proyecta y realiza la Contaduría y levanta la actualización de la traza urbana. En 1766 es nombrado Ingeniero en Jefe. (CAPEL, 1983, p. 227) 18 TEJEIRA, E. y SPADAFORA, V. El Casco Antiguo..., ibídem, p. 33.

${ }^{19}$ ESTUDIO A3, S.A. "Evolución Histórica Constructiva del Inmueble Compañía de Jesús - Casco Antiguo - Ciudad de Panamá", en Estudio y propuesta de uso integral para la rehabilitación del Conjunto de la Compañia de Jesús en el Casco Antiguo de la Ciudad de Panamá, Oficina del Casco Antiguo, 2012, pp. 7 - 9.

${ }^{20}$ CASTILLERO, Ernesto J. Convento y templo..., ibíd, p. 66.
} 
Invest. pens. crit. (ISSN 1812-3864)

Vol. 6, No. 2, mayo-agosto 2018

pp. $30-51$

los balcones corridos para transformar al edificio, en uno de inquilinato así como lo vemos en la actualidad. Ver Fig. $N^{\circ} 6$

Por otro lado, en cambio, la Iglesia Jesuita (Fincas 2476 y 3045) luego de su venta, se convirtió en establos, cobertizos e incluso, contuvo a dos casas en su interior; mientras que, la capilla mayor terminó por albergar una vivienda de dos pisos ${ }^{21}$. Entre 1918 y 1935, este templo funcionó como sinagoga albergando a la Congregación Kol Shearith Israel de Panamá. Ver Fig. $N^{\circ} 7$

Los años 70 y 80 del siglo XX fueron significativos para Panamá en la creación de instrumentos actuativos que permitieran la recuperación de la edilicia histórica. Por esta razón, se solicita la asesoría internacional del arquitecto restaurador mexicano Carlos Flores Marini quien desarrolla los Planes Maestros para la puesta en valor del Casco Antiguo de la Ciudad de Panamá (1972), del Sitio Arqueológico de Panamá Viejo y del Complejo de Fortificaciones de Portobelo $(1974-1977)^{22}$.

En 1979, la capilla mayor de la Iglesia o sacristía (Finca 3045) es adquirida por el IPAT - Instituto Panameño de Turismo (hoy en día, Autoridad de Turismo de Panamá - ATP y actual propietaria administrativa) y más adelante, los lotes de la Iglesia de la Compañía de Jesús (Finca 2476) y el Patio Central (Finca 2473) del complejo monumental.

En 1982, con la promulgación de la Ley N¹4 donde "se dictan medidas sobre la custodia, conservación y administración del Patrimonio Histórico de la nación”, se inicia un importante período de intervenciones de tipo restaurativo y conservativo para las construcciones monumentales más representativas del país. Entre ellas, la Iglesia de la Compañía de Jesús que recupera nuevamente su fachada y la plazoleta.

Actualmente, se busca revalorizar la Iglesia a través de un proyecto museal dedicado a la presencia de la Orden Jesuita en América Latina y a la Congregación Kol Shearith Israel en Panamá; mientras que, las edificaciones de la Universidad Javeriana (Fincas 2471 y 2479) de propiedad civil, serán destinadas a uso hotelero.

\section{Conclusiones $^{23}$}

Con el fraccionamiento y venta del Complejo Monástico de la Compañía de Jesús en cinco propiedades por el estado colombiano ${ }^{24}$ en 1865 , se agredió a sus condiciones de conjunto histórico del patrimonio religioso y educativo, así como, se produjo una fractura en el alcance de su futura tutela. Sus características únicas y representativas de la arquitectura de época colonial que además, formaron parte de los complejos conventuales que se implantaron en Panamá y que definieron la fisonomía urbana del Casco Antiguo son testimonio de la memoria histórica de la ciudad y del legado cultural

\footnotetext{
${ }^{21}$ ESTUDIO A3, S.A. "Evolución Histórica..., ibídem, p. 7

22 TEJEIRA DAVIS, Eduardo. Guía de Arquitectura y Paisaje de Panamá. Instituto Panameño de Turismo y la Junta de Andalucía. Panamá, 2007, pp. 174.

${ }^{23}$ Las siguientes reflexiones son del criterio personal de las autoras y no expresa las medidas adoptadas por la CONAMOH ni por la DNPH ante el caso del Conjunto monumental histórico de la Compañía de Jesús en el Casco Antiguo de la Ciudad de Panamá y están dirigidas al sector académico como caso de estudio sobre el alcance de la tutela del patrimonio arquitectónico monumental de Panamá.

${ }^{24}$ En aquel entonces, Estados Unidos de Colombia conformado por Colombia, Panamá y parte del territorio de Brasil y Perú. Estuvo constituido desde 1863 hasta 1886.
} 
Invest. pens. crit. (ISSN 1812-3864)

Vol. 6, No. 2, mayo-agosto 2018

pp. $30-51$

que la orden religiosa jesuita impartió en estas estructuras y que también se vieron afectados ante la desnaturalización de su conjunto.

Luego de la compra de las Fincas 2473, 2476 y 3045 por el IPAT en 1979, el Conjunto Jesuita quedó dividido en una propiedad del estado panameño (patio central, Iglesia y sacristía) y en dos propiedades privadas o civiles correspondientes a las Fincas 2471 y 2479 (edificios de la Universidad Javeriana). En la actualidad, la recualificación de la Manzana 29 ha provocado un análisis del alcance de la tutela nacional ante la división de las propiedades del complejo histórico monumental que ocupó la Orden de la Compañía de Jesús en Panamá durante el siglo XVIII y sus correspondientes nuevos usos.

Por esta razón, en mayo del 2015 la Comisión Nacional de Patrimonio Histórico (CONAMOH), organismo que asesora a la Dirección Nacional de Patrimonio Histórico (DNPH), determinó efectuar una investigación que identificase la relación histórico - arquitectónica y cultural entre las edificaciones en cuestión, así como, la realización de una inspección técnica al sitio para verificar los datos históricos de la investigación y complementar la información legal disponible para el adecuado análisis de este organismo. El material obtenido forma parte del Informe $\mathrm{N}^{\circ} 001$ - 2015 - CONAMOH de agosto de 2015 y se presenta en parte en este artículo a continuación, con una revisión y actualización de su información histórica y bajo la previa autorización de la CONAMOH para que sea utilizado en fines académicos.

En cuanto a los datos que resumen el orden cronológico de sus construcciones, tenemos lo siguiente:

Primera fase (1673 - 1737): 1 Colegio de San Javier (2479) e Iglesia de la Compañía de Jesús (2471)

Segunda fase (1737 - 1821): 1. Real y Pontificia Universidad de San Javier (Teología y Moral: 2479)

2. Real y Pontificia Universidad de San Javier (Filosofía: 2471)

3. Iglesia de la Compañía de Jesús (temporal: 2473)

4. Iglesia de la Compañía de Jesús (definitiva: 2476 y 3045)

Tercera fase $(1821$ - s.XX): $\quad$ 1. Casa de la Familia Obarrio, Hotel Washington, Club

Internacional y edificio de inquilinato (2479)

2. Edificio de inquilinato (2471)

3. Establos, cobertizos y dos residencias (2476)

4. Una residencia y sinagoga (3045)

La inspección técnica se efectuó a finales de mayo de 2015 con representantes de las respectivas autoridades (CONAMOH, DNPH y OCA) que salvaguardan el complejo histórico. A través de un reconocimiento de las estructuras y de un análisis arquitectónico y del sistema constructivo, se verificó lo siguiente:

1. Que los edificios de las Fincas 2479 (Teología y Moral) y 2471 (Filosofía) nacen de una estrecha relación a fines de la instrucción académica y moral impartida por la Orden Jesuita en ellos. Se construyen en el mismo momento y bajo las mismas técnicas constructivas identificadas por la información histórica fornita en el punto: Segunda fase constructiva: la 
Invest. pens. crit. (ISSN 1812-3864)

Vol. 6, No. 2, mayo-agosto 2018

pp. $30-51$

Real y Pontificia Universidad de San Javier, así como, por el testimonio gráfico que ofrece la Vista Volumétrica realizada por el ingeniero Nicolás Rodríguez en 1748, de la Ciudad de Panamá. VerFig. $N^{\circ} 3$.

En esta imagen, se puede apreciar que ambas edificaciones comparten las mismas características arquitectónicas en el momento de su creación: volúmenes entonacados o repellados con sillares de piedra a vista en las esquinas y con techos de tejas a 2 y 4 aguas, como parte de un mismo lenguaje arquitectónico en común.

Que el muro posterior actual de la Finca 2471 es el original del siglo XVIII, ya que, confirma la cantidad de pisos del volumen que aparece en la Vista Volumétrica realizada por el ingeniero Nicolás Rodríguez en 1748, a través de los antiguos vanos que aparecen en la actualidad tapeados ${ }^{25}$.

2. Que el edificio de la Finca 2471 era descrito hacia 1822 por el Capitán escocés Basilio Hall, como: “La ruina más linda es el Colegio de Jesuítas, grande y bello edificio [...]”. La descripción arquitectónica del edificio se presenta a continuación ${ }^{26}$ :

"[...] El colegio es gran edificio cuadrado, construido hasta la altura de dos pisos, probablemente para añadirle un tercero. La parte ornamental de la construcción es de gusto puro y sencillo: hermosas cornisas, con altas molduras, rodean la obra arriba y abajo de ventanas muy numerosas y divididas por columnas góticas; los ángulos también y las piedras en las puertas tienen molduras de relieve. De cada esquina del edificio y del medio de cada costado se alia una sólida torre cuadrada, descansando en arcos apoyados en el suelo, por donde pueden pasar rodados. En conjunto tiene apariencia compacta, maciza y graciosa, no desemejante a templo griego, aunque totalmente diferente en su estructura. Los detalles están ejecutados con primor y delicadeza, pero no bay ninguna fruslería de escultura ornamental, y todos los detalles parecen contribuir a la grandiosidad del conjunto. [...]"

Lo que indica, que de los edificios de la Real y Pontificia Universidad de San Javier de Panamá, éste era el más importante y representativo arquitectónicamente. El hecho de que el Capitán Hall lo describiera con dos pisos solamente, se debe a que lo encontró en ruinas en su parte frontal. El edificio ya había sufrido el fuego de 1781 donde las estructuras en madera (entre ellas el techo), seguramente, habían sido consumidas. Su apariencia maciza y su portal de columnas y arcos en planta baja puede ser comparado con las características arquitectónicas de la Aduana de Portobelo. Pero, sus descripciones y la documentación fotográfica de sus restos, identifican lineamientos decorativos de mayor riqueza estética. Su relación de conjunto, se aprecia incluso entre las 3 torres que se destacaban (los extremos del edificio universitario y la torre de la Iglesia) creando de este modo, una fachada de lectura única, continua e imponente de gran importancia dentro del contexto urbano de la zona y con un lenguaje arquitectónico uniforme, como era la intención de la Orden Jesuita al realizar una edificación de instrucción superior que debía competir con las Universidades de Quito y de Lima. Ver Fig. No 8

3. Que el edificio de la Finca 2471 pasa por varias modificaciones constructivas desde su fundación en 1741. El edificio principal, el más importante por albergar a la Cátedra de

25 Por tratarse de una propiedad privada, no se incluye la imagen.

${ }^{26}$ HALL, Basilio. La Ciudad de Panamá en 1822. Revista Lotería N44, enero de 1945, pp.12. 
Invest. pens. crit. (ISSN 1812-3864)

Vol. 6, No. 2, mayo-agosto 2018

pp. $30-51$

Filosofía, se aprecia en la Vista Volumétrica y en el Plano de la Ciudad de Panamá de mediados del siglo XVIII del ingeniero Nicolás Rodríguez, con 4 pisos de alto en total y un volumen frontal de dos pisos con techo de tejas el cual, poseía un portal con arcos y columnas.

Posteriormente, el volumen frontal de arcadas aumentará un piso y cambiará su fisonomía contrastando con las descripciones del siglo XIX hechas por Basilio Hall, ya que, con el terremoto de 1882, el edificio se verá fuertemente afectado. Su última transformación proviene del siglo XX donde las características de su imponente fachada frontal desaparecen por completo, así como, el nivel de sus pisos interiores para permitir apartamentos de inquilinato. Ver Fig. No9

Según la documentación fotográfica histórica analizada y de la fotografía de E. Muybridge, se aprecia que después del terremoto de 1882 todavía resta en pie y en mejor estado, el sector unido a la Iglesia de la Compañía de Jesús donde corresponde el ingreso lateral derecho de la Universidad Javeriana. Esto nos permite observar parte de la riqueza de la ornamentación arquitectónica que poseía este edificio y la escala monumental del conjunto. Ver Fig. $N^{\circ} 10$

En el presente y de acuerdo con información fotográfica brindada por la DNPH para el análisis de la Comisión, sólo nos queda parte de la clave central en la trabeación con el grabado del año de 1739 (probable año de inicio de la construcción de la Universidad) y parte del arco que formaba el portal del ingreso derecho hacia Avenida A y que conectaba lateralmente con la plazoleta de ingreso a la Iglesia.

4. Que el edificio de la Finca 2479, primer edificio del Complejo del siglo XVIII y dedicado a la Cátedra de Teología y Moral de la antigua Universidad Jesuita, también pasó por varias modificaciones constructivas desde su terminación en 1741 pero, en su fachada frontal hacia la Calle 8va Oeste, conservó una arquitectura de extrema simplicidad a lo largo del tiempo. Ver Fig. $N^{\circ} 5$

En la Vista Volumétrica y en el Plano de la Ciudad de Panamá de mediados del 1700 del ingeniero Nicolás Rodríguez, el edificio se aprecia con 3 pisos de alto en total como en la actualidad (ver Fig. $N^{\circ} 3$ ) pero, sin los balcones posteriores existentes y tal vez, tampoco los frontales, ya que, en la culminación del edificio de la finca 2479 en la Vista Volumétrica, se observan ambos aleros del techo al borde del edificio y ninguna silueta que refleje que hayan existido los balcones corridos junto con las delgadas columnas de madera que se observan hoy en día.

Durante el siglo XIX el edificio es modificado para ser adaptado a funcionar como Hotel Washington o como el Club Internacional. No se ha encontrado información que ayude a precisar la realización de los balcones de la fachada frontal.

5. Que existieron tres (3) edificaciones eclesiásticas en el polígono de la Compañía de Jesús. La primera fue una iglesia que se ubicó en lo que, es hoy la Finca 2471 y que resale hacia las últimas décadas del 1600. Según la investigación histórica realizada, el edificio era de una cierta importancia arquitectónica, aunque no se encontró información más detallada al respecto. El segundo edificio se refiere a una capilla provisional realizada en madera hacia 1740 y ubicada 
Invest. pens. crit. (ISSN 1812-3864)

Vol. 6, No. 2, mayo-agosto 2018

pp. $30-51$

en el Patio del Complejo, actualmente, la Finca 2473. Y el tercer edificio es la iglesia actual, iniciada su construcción en 1761 y en la Finca 2476. Ver Fig. Nº1, 2 y 4

6. Que la información histórica correspondiente a los materiales de construcción de la Iglesia en las Fincas 2476 y $\mathbf{3 0 4 5}$ (piedra y ladrillos) detallados en el punto: Segunda fase constructiva: Iglesia de la Compañía de Jesús, ha sido confirmada por la Inspección Técnica realizada al sitio. Y que ambas fincas son parte de un único edificio que además, utiliza las mismas técnicas constructivas en todas las edificaciones del Complejo Jesuita.

La división actual de las propiedades que conforman el Complejo Monástico de la Compañía de Jesús ha ocasionado una contradicción en los términos de la tutela local, ya que, su alcance para una fábrica de tipo religioso y de instrucción académica y de formación moral sólo lo concibe en el caso de la Iglesia Jesuita y no abarca al Complejo completo dejando al sector conventual bajo una definición de términos distinta. Esto comporta que la legislación observe a la fábrica desde la condición de "monumento" de modo individual y venga aplicada de forma particularizada a cada edificación.

De este modo, la línea de partida es la Ley $\mathrm{N}^{\circ} 91$ del 22 de diciembre de $1976^{27}$ que en su Artículo 2 define el concepto de "Monumento Histórico" para el Casco Antiguo, como sigue:

"Considérase monumento histórico el edificio o conjunto de construcciones homogéneas conservados integros o en ruinas y que constituyen una unidad de reconocido valor arquitectónico, histórico y estético." [el subrayado y resaltado es nuestro]

Este concepto entra en conflicto en el momento en que es asignado el grado de protección de las edificaciones de acuerdo con el Manual de Normas y Procedimientos para la Restauración y Rehabilitación del Casco Antiguo de la Ciudad de Panamá ${ }^{28}$. En síntesis, de las cinco propiedades que conforman el Complejo Jesuita, el edificio principal y de mayor representación de la Universidad Javeriana (2471) por su alto valor histórico y cultural es el principal afectado al recibir una clasificación menor a las demás: Edificación de Segundo Orden; mientras que, el resto de los edificios son de Primer Orden ${ }^{29}$. Lo que, evidencia que la clasificación no fue contemplada para un "conjunto de construcciones homogéneas" de acuerdo con la definición del Artículo 2 de la L. 91/1976 ocasionando así, la pérdida de su valor ambiental como una unidad urbana religiosa del centro histórico y coherente con sus características.

Sumado a esto, la división entre propiedades del estado (Iglesia: 2476, 3045 y 2473) y propiedades civiles (Universidad: 2471 y 2479) han llevado a determinar un tipo de usos distinto siendo sólo las primeras, a entrar en una protección y preservación de sus usos internos normadas por la zonificación SIU (Zona de Servicio Institucional Urbano) de la regulación urbana ${ }^{30}$ del 2003 y que en su Artículo 12 describe lo que está permitido:

$$
\text { " }[\ldots]
$$

${ }^{27}$ Gaceta Oficial de Panamá N¹8252. L. Nº1/1976 por la cual, se regulan los Conjuntos Monumentales Históricos de Panamá Viejo, Portobelo y el Casco Antiguo de la Ciudad de Panamá.

${ }^{28}$ G.O.P. N²5039. Decreto Ejecutivo N 51 del 22 de abril del 2004.

${ }^{29}$ D.E. $N^{\circ}$ 51/2004, Título III, Capítulo I, Sección II, Artículo 128.

30 Resolución MIVI N²127 de 25 de agosto de 2003 por la cual, se aprueba la zonificación del uso del suelo y normas edificatorias para el Casco Antiguo de la Ciudad de Panamá. 
Invest. pens. crit. (ISSN 1812-3864)

Vol. 6, No. 2, mayo-agosto 2018

pp. $30-51$

Construcción, reconstrucción, restauración, reparación y conservación de edificios destinados al servicio de salud, de la educación, seguridad, cultura, deportes, administración y a servicios religiosos, a nivel urbano."

Mientras que, para las propiedades civiles (ya en un contraste de órdenes) con una zonificación tipo RMH1-C2 (Zona Residencial Multifamiliar de Alta Densidad "RMH1" y Zona Comercial de Alta Densidad “C2”), está permitido lo siguiente:

"Articulo 7: Para la Zona Residencial Multifamiliar de Alta Densidad (RMH1) [...] Usos permitidos:

a) Construcción, reconstrucción, restauración y reparación de edificios destinados a viviendas unifamiliares y multifamiliares y sus usos complementarios como oficinas de profesionales residentes.

b) Se permitirán Usos Institucionales como edificios docentes, religiosos, culturales, gubernamentales, filántropicos, y asistenciales, siempre que dichos usos no constituyan perjuicio a los vecinos o afecten en forma adversa el carácter residencial de la zona.

[...]

Artículo 10: para la Zona Comercial de Alta Densidad (C2) [...]

Usos permitidos:

a) Construcción, reconstrucción, restauración y reparación de edificios destinados a instalaciones comerciales y profesionales (venta al por mayory al por menor de articulos de vestir, muebles, articulos para el hogar, articulos eléctricos, articulos electrónicos, viveres y telas, restaurantes, agencias de viajes, lavanderías, aseguradoras, galerías de arte, servicios de telecomunicaciones, inmobiliarias, clinicas de salud, librerías, agencias de correos, agencias de seguridad, cines, teatros, ferreterías, sucursales de bancos, discotecas, gimnasios, clubes deportivos, clubes culturales, papelerías, financieras, hoteles, aparthoteles, edificios de alquiler de estacionamientos, depósitos, talleres de reparación de aparatos eléctricos y oficinas administrativas, sala de éstetica), siempre y cuando no perjudiquen al Carácter Patrimonial del área.

$[\ldots] ”$

La problemática se hace nuevamente presente cuando es aplicado el Artículo 13 de la L. 91/1976, que además de, definir y asignar la cualidad de "monumento histórico" dentro de un conjunto monumental (en este caso, el Casco Antiguo), señala entre los siguientes efectos para éstos, lo siguiente:

"d) Sólo podrán destinarse a usos compatibles con su condición de monumentos históricos, como lo religioso Y

cultural. El Consejo [ ${ }^{31}$ ] deberá ser consultado al respecto y toda intervención física necesaria para su uso deberá ajustarse a las normas internacionalmente aceptadas sobre el particular y se ajusten a las circunstancias ambientales e históricas de Panamá y hayan sido aprobadas y ratificadas formalmente.

[...]" [el subrayado y resaltado es nuestro].

Lo que, indica que para todo el Complejo Monástico de la Compañía de Jesús (y no sólo la Iglesia) debería haber sido asignado un uso compatible con su monumentalidad que, además, viene determinado por la Ley como "religioso y cultural", y que concibe al uso comercial como no aceptable por la Ley 91/1976. Si vamos más atrás, una primera tutela local para este Complejo, se podría

31 El "Consejo" referido al "Consejo Nacional de Conjuntos Monumentales Históricos", organismo asesor del Instituto Panameño de Turismo (IPAT) al momento de la publicación de la Ley, pasará a llamarse "Comisión Nacional de Arqueología y Monumentos Históricos (CONAMOH)" a partir de la Ley N¹4 de 5 de mayo de 1982 y asesora a la Dirección Nacional de Patrimonio Histórico del Instituto Nacional de Cultura en la actualidad. 
Invest. pens. crit. (ISSN 1812-3864)

Vol. 6, No. 2, mayo-agosto 2018

pp. $30-51$

interpretar en la Ley 67 de 11 de junio de $1941^{32}$ identificándolo como monumento arqueológico y propiedad de la nación panameña, así como, los hallazgos que en éste se encontrasen los cuales, no podrían ser sujetos a la comercialización ni tampoco sus estructuras.

Además de esto, la letra "d" del Artículo 13 agrega que las intervenciones deberán ajustarse a las "normas internacionales aceptadas" lo que va dirigido hacia 2 campos: el técnico y el de tutela. En cuanto a este último, directamente, interviene la tutela UNESCO a la cual, está inscrito el Casco Antiguo $^{33}$ desde 1997 bajo los criterios II, IV y VI, así como, también viene corroborado el Art. 13 de la L. 91/1976 por el Manual de Normas del Casco Antiguo (D.E. N 51/2004) que en su Capítulo I, Artículo 5 dice:

"Se entenderá que todas las propiedades existentes dentro de los límites del Casco Antiguo estarán protegidas y amparadas por la Inscripción del Comité del Patrimonio Mundial de la Organización de las Naciones Unidas para la Educación, la Ciencia y la Cultura (UNESCO), del 6 de diciembre de 1997, en la lista del patrimonio mundial y en el cual se confirma el valor excepcional y universal del sitio para el beneficio de la bumanidad, además de cualquier otra normativa legal vigente en la República de Panamá."

[el subrayado es nuestro].

Para conocimiento y estudio, se citan a continuación los criterios inscritos por Panamá ante UNESCO y que reconocen el Valor Universal Excepcional de todas las propiedades ubicadas dentro del Casco Antiguo, así como, las Declaraciones de Autenticidad e Integridad ${ }^{34}$ que lo rigen actualmente y que hacen referencia a la tutela del caso en cuestión:

"Criterio (ii) ${ }^{35}:$ [... El El diseño del Distrito Histórico refleja la persistencia e intercambio de valores bumanos, que se han orientado hacia las comunicaciones interoceánicas e intercontinentales durante varios siglos en este sitio estratégico del Istmo Centroamericano." [el subrayado es nuestro]

"Criterio (iv) ${ }^{36}$ : Tanto en Panamá Viejo como en el Distrito Histórico, los tipos de casas e iglesias desde el siglo XVI hasta el siglo XVIII, representan una etapa significativa en el desarrollo de la sociedad colonial española en su conjunto. [...]” [el subrayado es nuestro]

"Declaración de Integridad"

\footnotetext{
32 G.O.P. N08538. L. N67/1941 por la cual, se dictan varias disposiciones relacionadas con los monumentos y objetos arqueológicos.

${ }^{33}$ El Casco Antiguo de la Ciudad de Panamá está inscrito a la Lista del Patrimonio Mundial UNESCO desde 1997. A partir del 2003, se amplía su jurisdicción al incluir a Panamá Viejo. Desde ese entonces, la unión de ambas propiedades será llamada "Archaeological Site of Panamá Viejo and Historic District of Panamá" (C-790bis)

34 WHC 13/37.COM/8E.ADD

35 "Criterion (ii): [...] The Historic District's layout reflects the persistence and interchange of buman values, which bave been oriented towards interoceanic and intercontinental communications for several centuries at this strategic site on the Central American Isthmus."

36 "Criterion (iv): In both Panamá Viejo and the Historic District, house and church types from the 16th to the 18th centuries represent a significant stage in the development of Spanish colonial society as a whole. [...]"

37 "Statement of Integrity:

[...]

The Historic District maintains, within its boundaries and those of the locally - protected adjacent area, a sufficient representation of all the atributes that convey Outstanding Universal V alue, particularly the urban layout, the dimension and distribution of ground plots, the remaining colonial fortifications and non - residential buildings of monumental value [...]”
} 
Invest. pens. crit. (ISSN 1812-3864)

Vol. 6, No. 2, mayo-agosto 2018

pp. $30-51$

$[\cdots]$

El Distrito Histórico mantiene, dentro de sus límites y de aquellos de la zona adyacente a protegida a nivel local, una representación suficiente de todos los atributos que transmiten Valor Universal Excepcional, particularmente la traza urbana, la dimensión y distribución de lotes de terreno, las fortificaciones coloniales restantes y edificios no residenciales de valor monumental [...]" [el resaltado y subrayado es nuestro]

Si bien es posible encontrar discrepancias entre las normas de tutelas, por otro lado, es fundamental la asesoría especializada para poder afrontar las problemáticas que se generan. La protección del bien monumental estará dirigida a evitar que se provoquen daños irreversibles durante la fase de intervención restaurativa o conservativa con la finalidad de, preservar el significado arquitectónico del bien, así como, de sus altos valores históricos y culturales.

La continuidad de sus funciones como inmueble podrá contrastar, en algunos casos, con las necesidades actuales que conllevan el empleo de un nuevo uso, ya sea, por la destinación de los espacios a nuevas actividades muy distintas a las originales, por los sistemas tecnológicos a incorporar o por la capacidad de soporte de sus estructuras históricas. Por esta razón, deberá también ser observada con atención, la asignación de nuevos usos para que se evite un impacto negativo a la edificación antigua desde el aspecto técnico hasta el plano cultural a tramandar. Encontrar soluciones adecuadas permitirá no sólo recuperar el monumento sino también, preservar sus valores a través de una nueva historia a escribirse.

\section{Agradecimientos}

Comisión Nacional de Arqueología y Monumentos Históricos - CONAMOH y Dirección Nacional de Patrimonio Histórico - DNPH del Instituto Nacional de Cultura - INAC. 


\section{Imágenes}

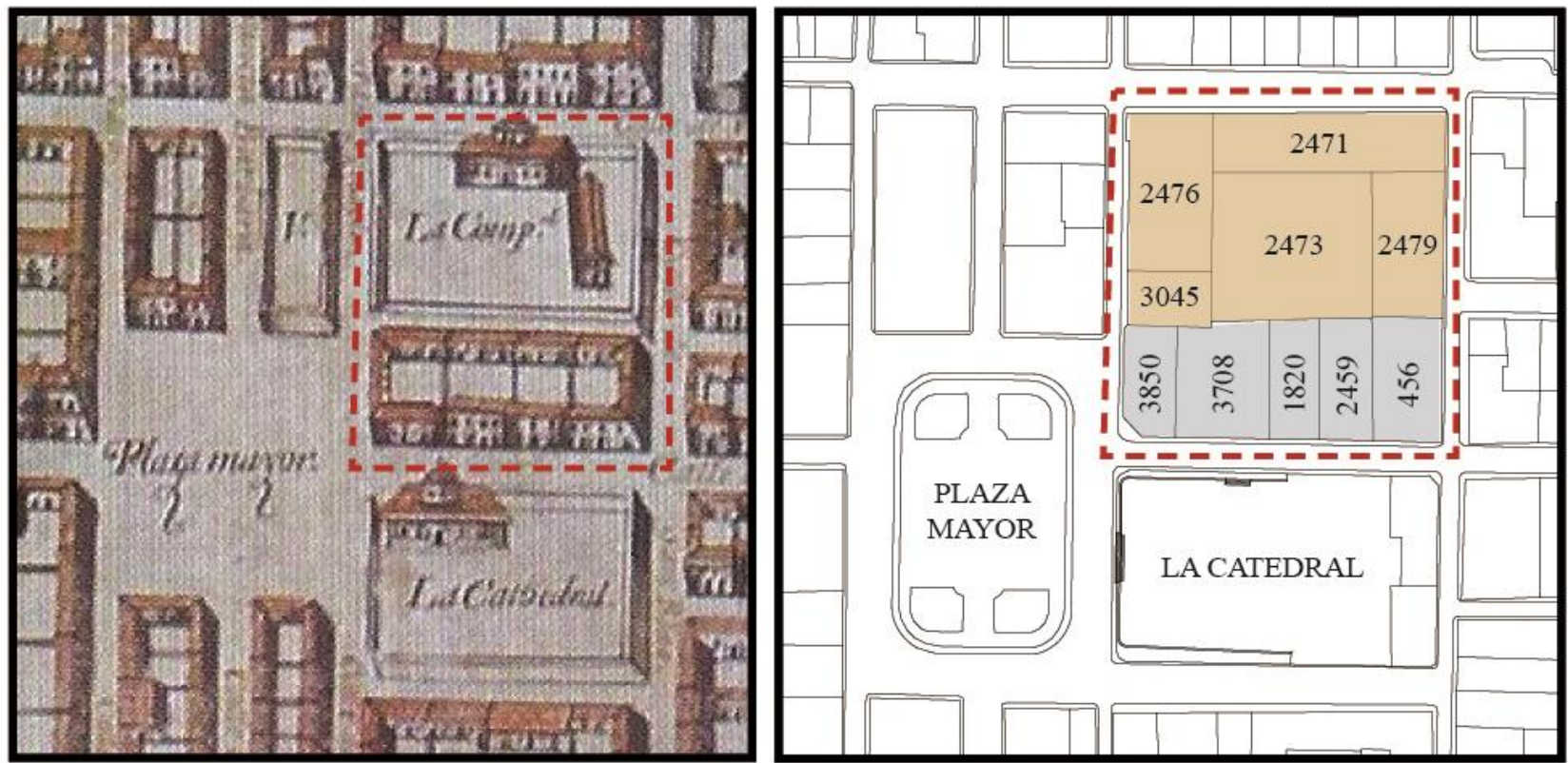

Figura N¹. Izquierda: Ubicación del Complejo de Jesús en el Mapa de la Ciudad de Panamá de 1688 dibujado por el ingeniero militar Bernardo de Ceballos y Arce. Derecha: En café, el Complejo Jesuita y en gris, edificaciones restantes que conforman la actual Manzana 29. La línea segmentada en rojo identifica la delimitación de la Manzana 29 en ambas imágenes.
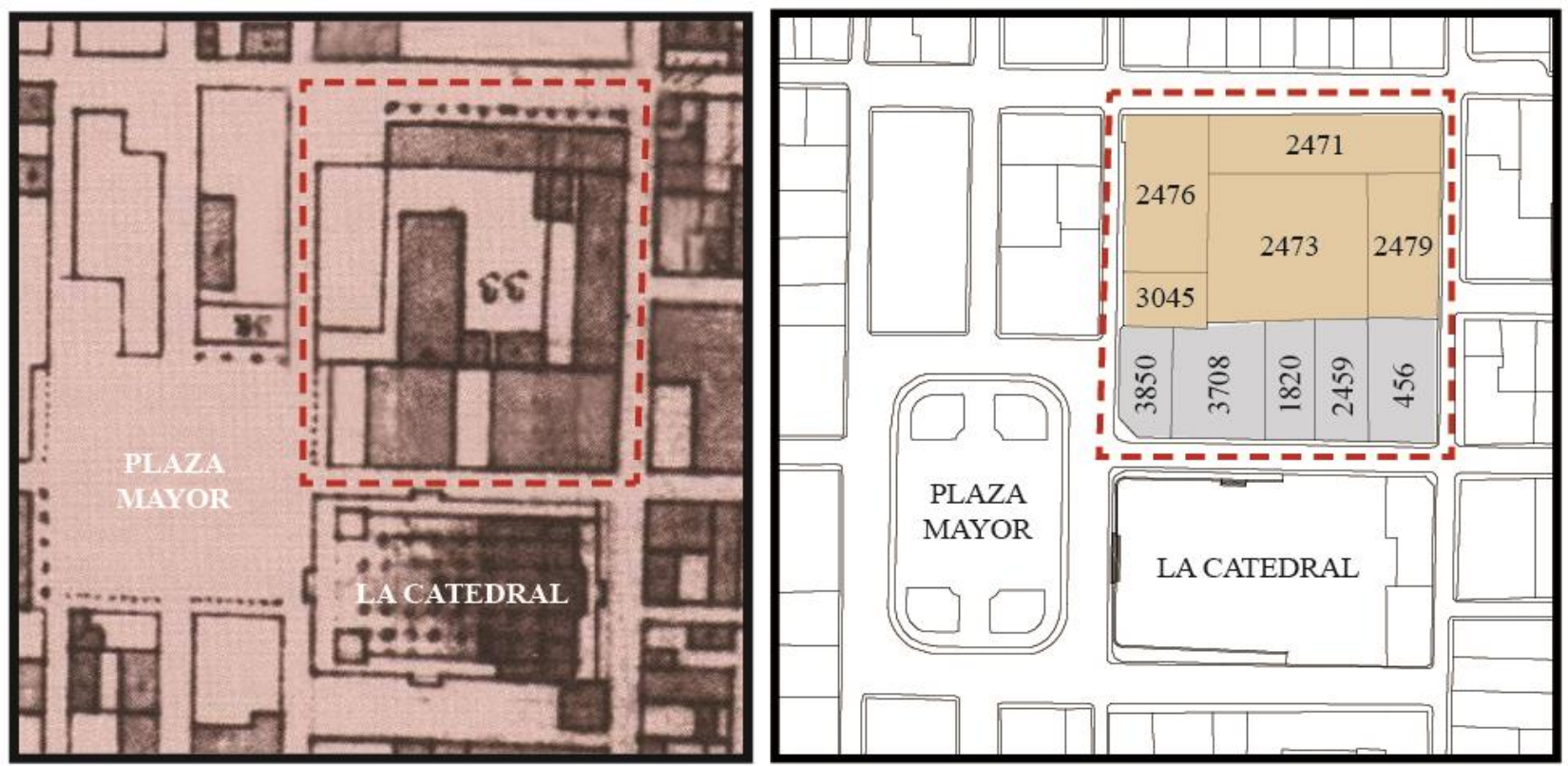

Figura N². Izquierda: Ubicación del Complejo de Jesús en el Mapa de la Ciudad de Panamá de 1749 dibujado por el ingeniero militar Nicolás Rodríguez. Derecha: la actual Manzana 29. La línea segmentada en rojo identifica la delimitación de la Manzana 29 en ambas imágenes. 
Invest. pens. crit. (ISSN 1812-3864)

Vol. 6, No. 2, mayo-agosto 2018

pp. $30-51$

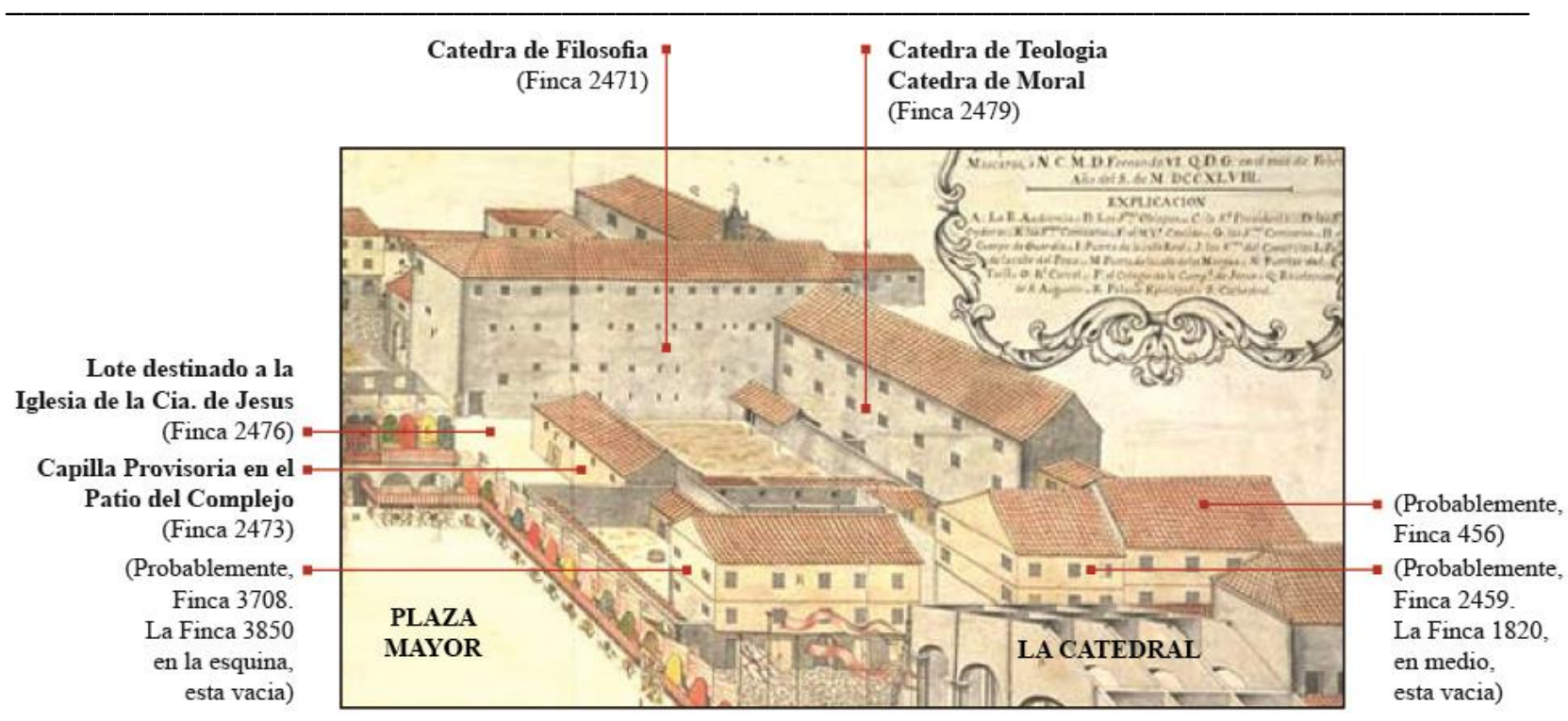

Figura N³. Vista volumétrica de la Real y Pontificia Universidad de San Javier de Panamá realizada por el ingeniero militar Nicolás Rodríguez de 1748. Se incluye la identificación de las propiedades actuales.

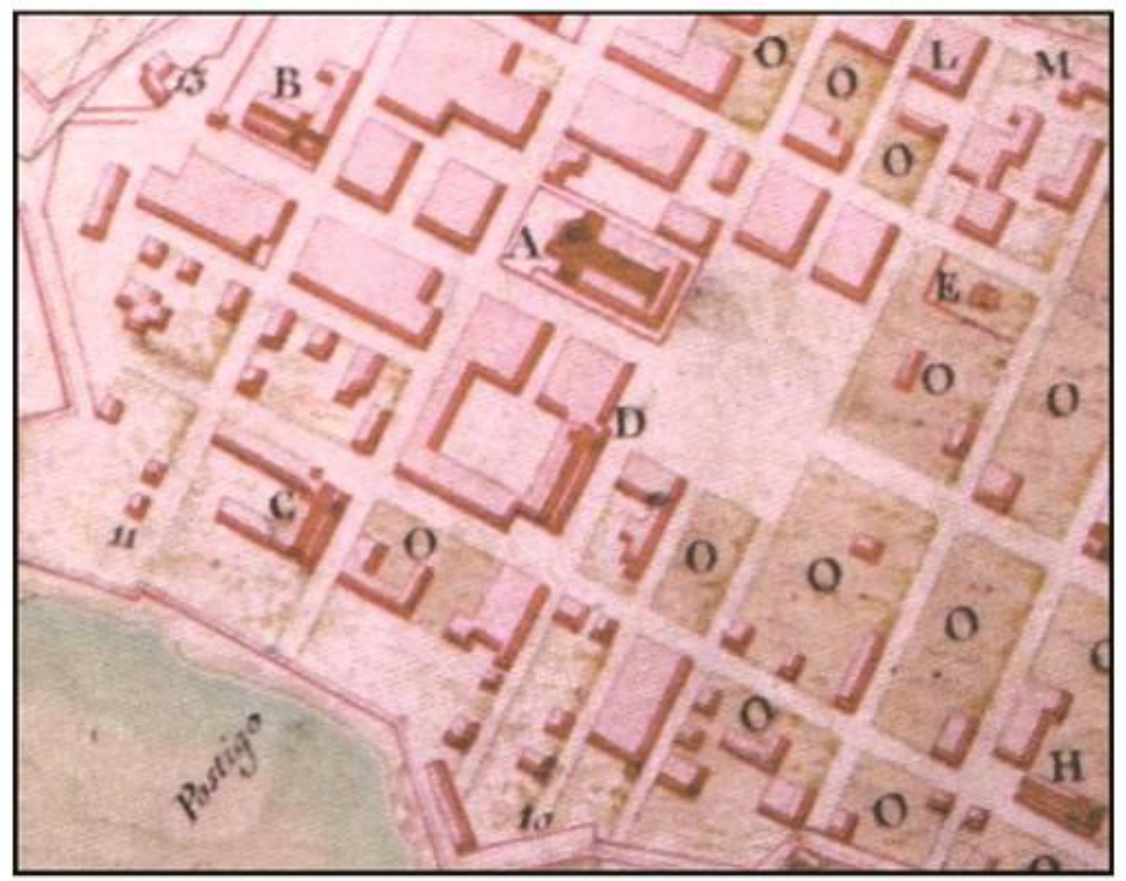

Figura N4. Detalle del plano de la Ciudad de Panamá realizado por el ingeniero militar Manuel Hernández en 1765. La ubicación de la Iglesia del Complejo Jesuita se aprecia representada con la letra "D". 


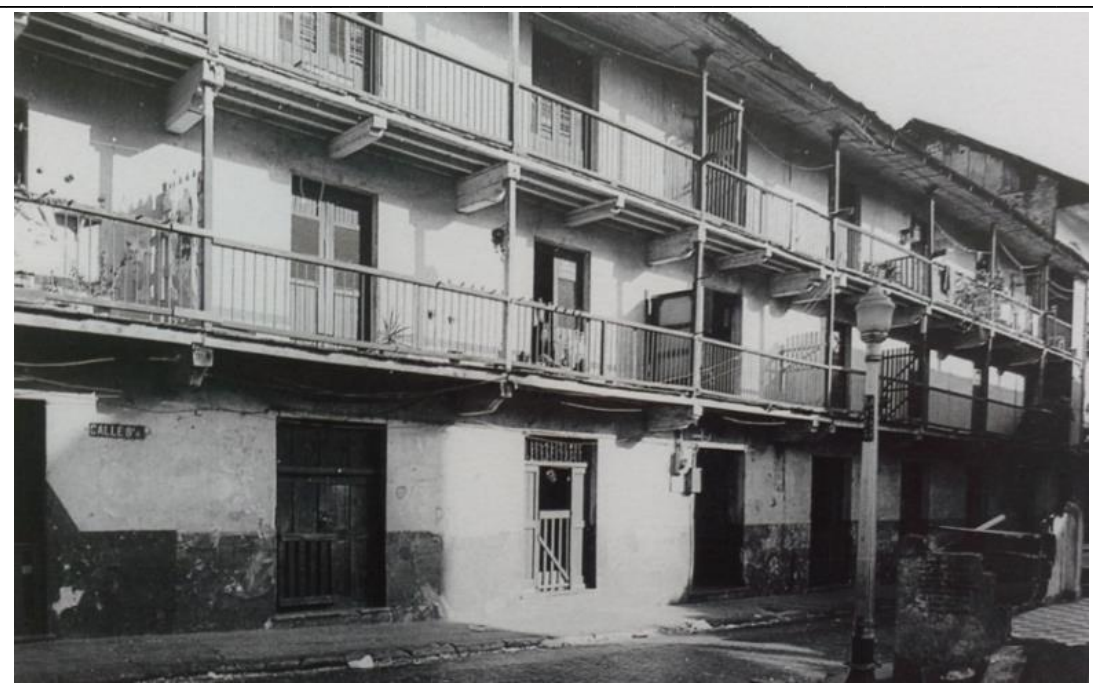

Figura N5. Fachada principal del edificio de las Cátedras de Teología y Moral de la Real y Pontificia Universidad de San Javier en la Calle $8^{a}$ Oeste, con modificaciones posteriores (vanos de puerta ventanas, balcones corridos y cubierta de techo en zinc) realizadas, posiblemente, durante el siglo XX para los nuevos usos. Fachada del Hotel Washington, del Club Internacional y por último, edificio de inquilinato durante el siglo XX. Fotografía: E. Tejeira, 1986
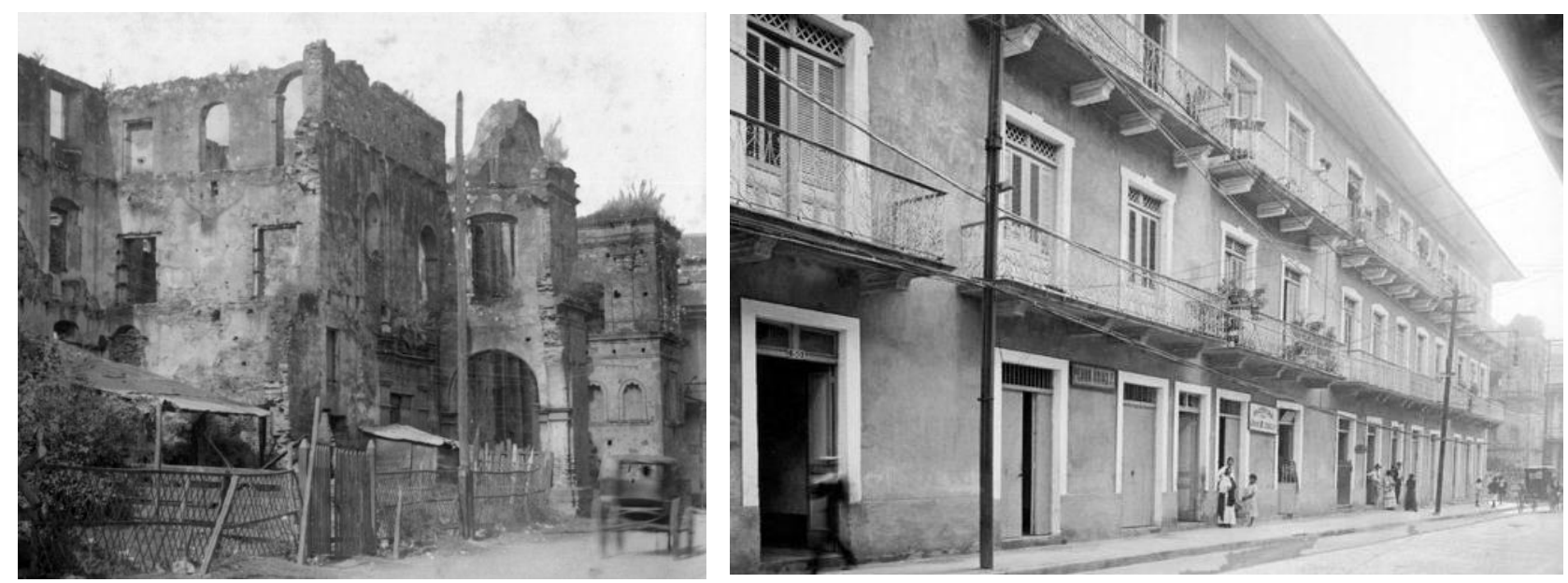

Figura No6. Vistas del antes y después del terremoto de 1882, los efectos (izquierda) y la transformación arquitectónica (derecha) al edificio de la Cátedra de Filosofía de la Real y Pontificia Universidad de San Javier. Fotografías: Eadweard Muybridge (izquierda) y Carlos Endara Andrade (derecha) de la Colección de Ricardo López Arias. 
Invest. pens. crit. (ISSN 1812-3864)

Vol. 6, No. 2, mayo-agosto 2018

pp. 30-51

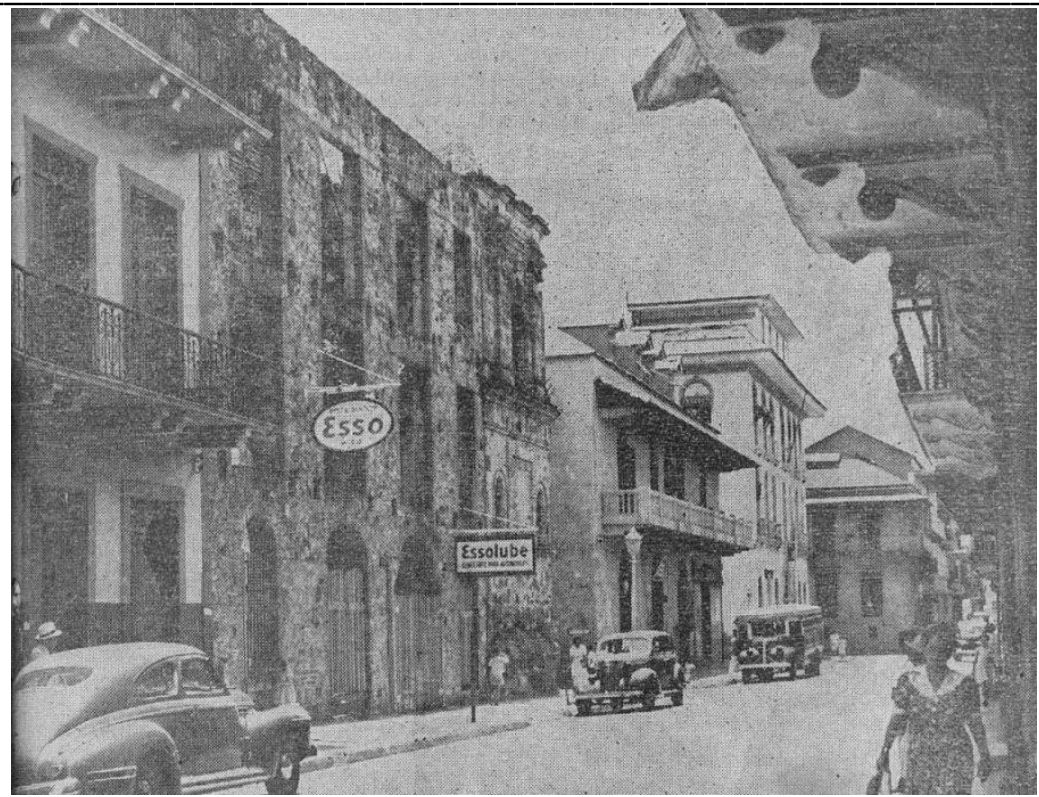

Figura N7. Fotografía de 1943 publicada en la Revista Lotería $N^{\circ} 27$, donde se aprecia la Iglesia de la Compañía de Jesús en estado de abandono y con un muro construido para unir el edificio de la Real y Pontificia Universidad de San Javier a la torre de la iglesia ocupando la plazoleta de ingreso.
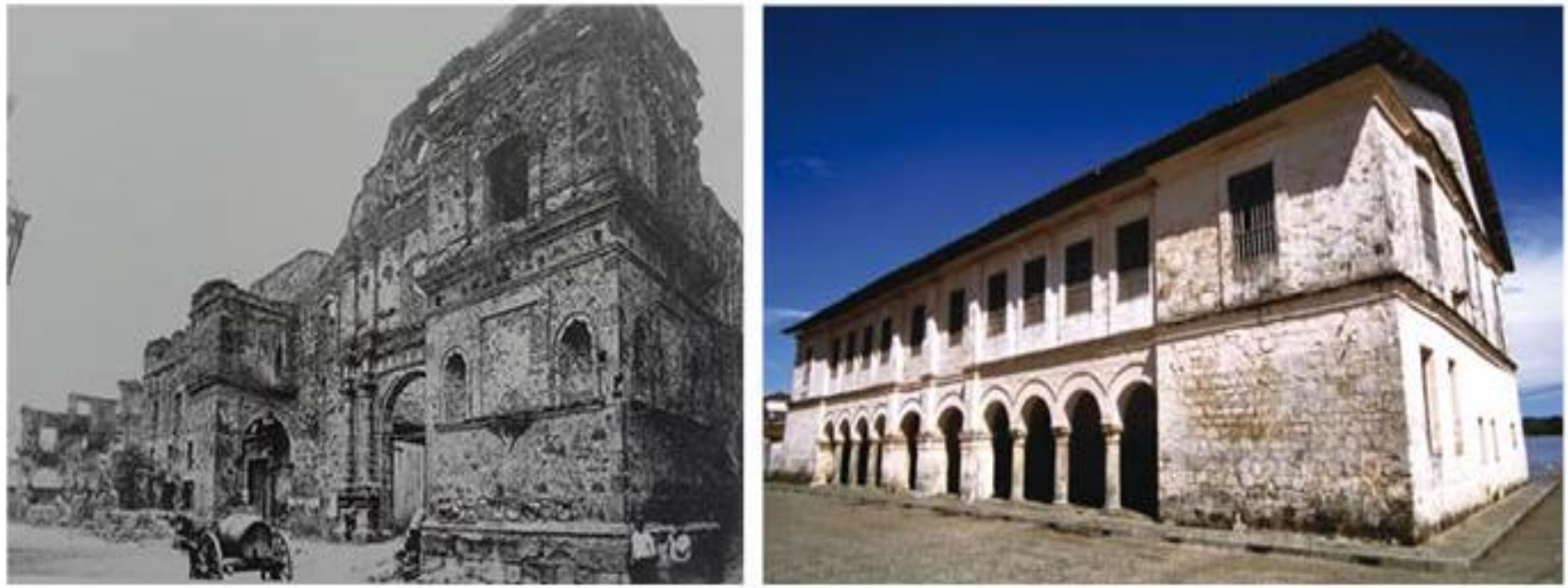

Figura N8. Análisis comparativo arquitectónico. Fotografías: Conjunto de la Compañía de Jesús en ruinas (izquierda) por E. Muybridge y Aduana de Portobelo (derecha) tomada en internet y de autor desconocido. 

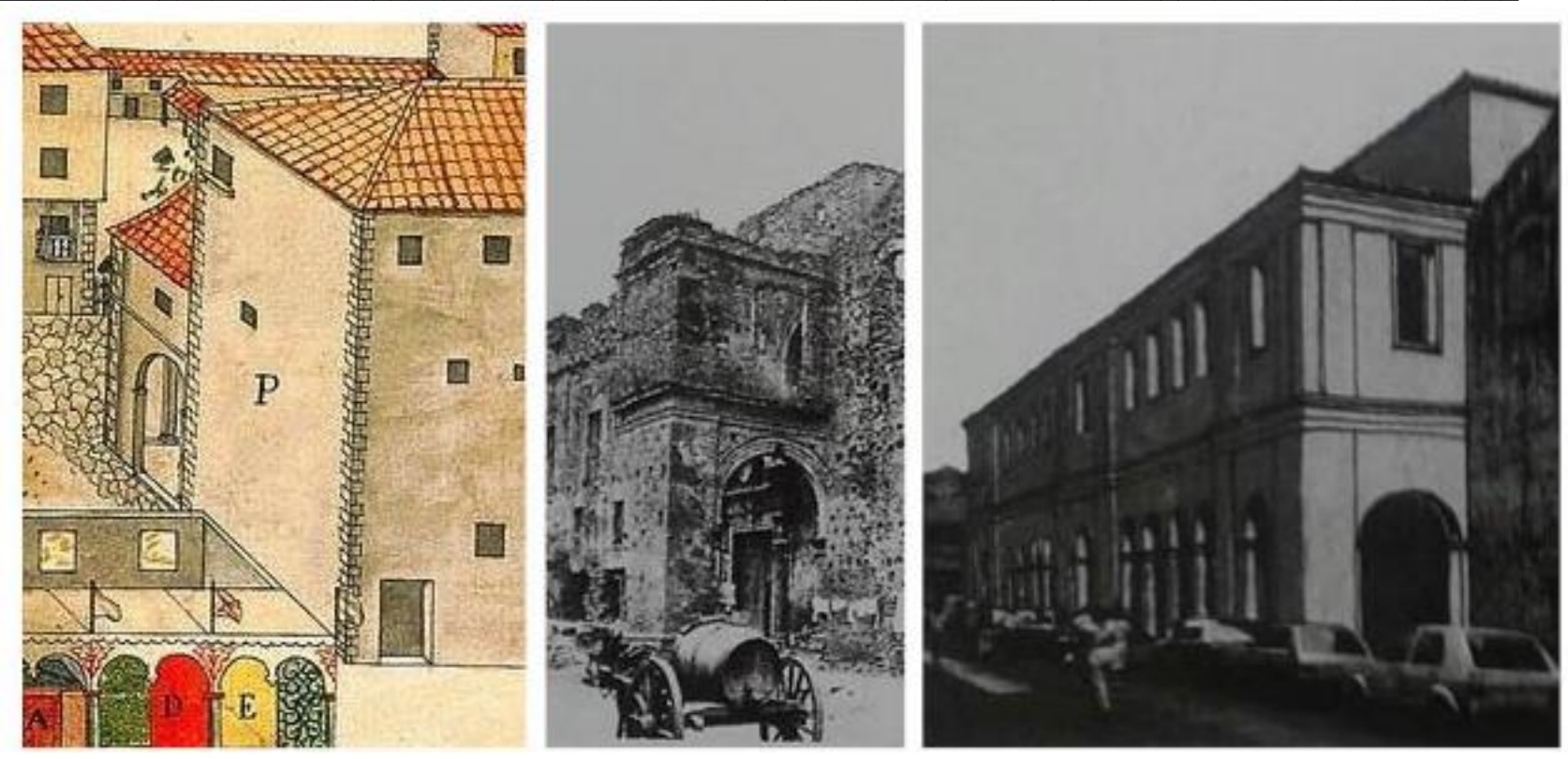

Figura N9. Izquierda: Detalle de la Vista Volumétrica de Nicolás Rodríguez, 1748. Centro: Fotografía de E. Muybridge. Derecha: Hipótesis del Arq. Eduardo Tejeira publicada en el libro "El Casco Antiguo de la Ciudad de Panamá”, 2001.

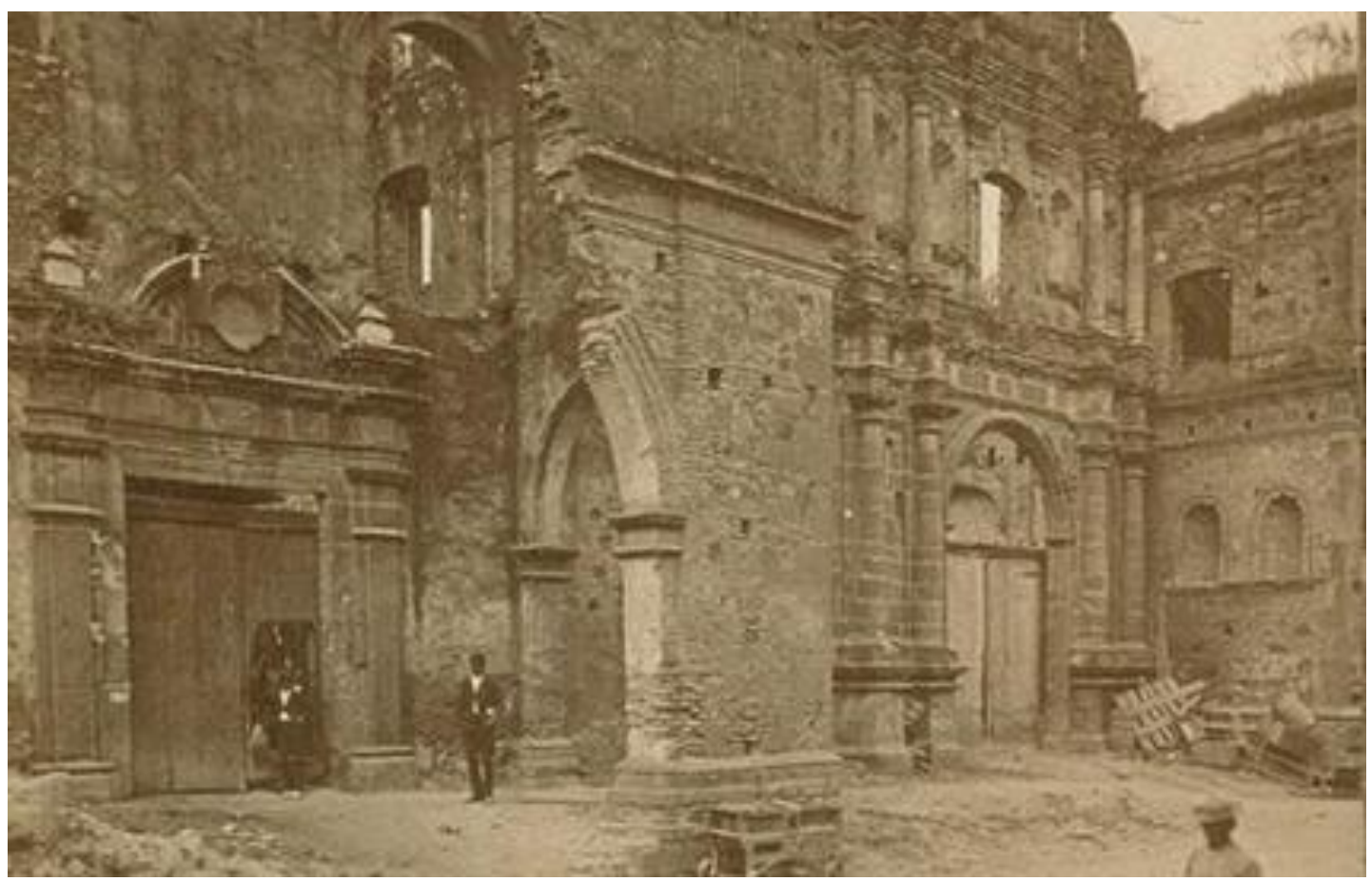

Figura $\mathbf{N}^{\circ}$ 10. Ingreso monumental derecho de la Real y Pontificia Universidad de San Javier (izquierda) y fachada de la Iglesia de la Compañía de Jesús (derecha). Fotografía de E. Muybridge. 
Invest. pens. crit. (ISSN 1812-3864)

Vol. 6, No. 2, mayo-agosto 2018

pp. $30-51$

\section{Bibliografía}

BORDA, José Joaquín. Historia de la Compañia de Jesús en la Nueva Granada. Poissy Imprenta de S. Lejay et $\mathrm{C}^{\mathrm{a}}$, vol. 1., 1872

CAPEL, Horacio y otros. Los Ingenieros Militares en España Siglo XVIII. Edicions Universitat de Barcelona. Barcelona, 1983

CASTILLERO, Ernesto J. Convento y templo de la Compañía de Jesús. Revista Lotería Nº183, febrero de 1971

ESTUDIO A3, S.A. "Evolución Histórica Constructiva del Inmueble Compañía de Jesús - Casco Antiguo - Ciudad de Panamá", en Estudio y propuesta de uso integral para la rehabilitación del Conjunto de la Compañia de Jesús en el Casco Antiguo de la Ciudad de Panamá, Oficina del Casco Antiguo, Panamá, 2012

HALL, Basilio. La Ciudad de Panamá en 1822. Revista Lotería N44, enero de 1945

JOUANEN S.I., José. Historia de la Compañia de Jesús en la antigua Provincia de Quito 1570 - 1773, Tomo II, La Provincia de Quito, 1696 - 1773. Editorial Ecuatoriana, 1943

MALLET, Lady. Sketches of spanish colonial life in Panama. Sturgis and Walton Company, New York, 1915

MANCERA CASAS, Jaime Alberto y otros. Arquidiócesis de Bogotá, 450 años: Miradas sobre su historia. Arquidiócesis de Bogotá y Universidad Santo Tomás, Ediciones USTA, Bogotá, 2015

MENA GARCIA, Carmen. Panamá en el siglo XVIII: trazado urbano, materiales y técnica constructiva. Revista de Indias, vol. LVII, núm. 210. Departamento de Historia de América, Universidad de Sevilla, 1997

TEJEIRA DAVIS, Eduardo. Guía de Arquitectura y Paisaje de Panamá. Instituto Panameño de Turismo y la Junta de Andalucía. Panamá, 2007

TEJEIRA, Eduardo y SPADAFORA, Vanesa. El Casco Antiguo de la Ciudad de Panamá. Oficina del Casco Antiguo. Panamá, 2001 